\title{
Shear Strength between HPC and Rolled Steel Plateafter Elevated Temperatures
}

\author{
Weiping Zhao ${ }^{1 \mathrm{a}}$, Sijia Yin ${ }^{1 \mathrm{~b}}$, Binrong Zhu ${ }^{2 \mathrm{c}}$, Renjie Chen ${ }^{1 \mathrm{~d}}$ \\ ${ }^{1}$ School of Mechanics and Civil Engineering, China University of Mining and Technology, Beijing, \\ 100083, China \\ ${ }^{2}$ China Electric Power Research Institute, Haidian District, Beijing 100192, P.R. China. \\ aemail: \\ weipingzhao163@163.com, b974707977@qq.com, cemail:amzhubr@163.com, d1450594718@qq. \\ com
}

Keywords:high-performance concrete (HPC); elevated temperature; shear strength; mechanical properties; rolled steel plate

\begin{abstract}
This paper had developed C100 high-performance concrete (HPC). Mechanical properties of high-performance concrete after evaluated temperatures were investigated. Besides, this paper had summarized the extrinsic characteristics of HPC after evaluated temperatures, which was effectively applied in evaluating the temperature experience of concrete structures. Shear strength between HPC and rolled steel plate after evaluated temperatures was experimentally studied with the facilities of specially designed loading device. Mathematical model of shear strength was proposed, which can be used in both engineering and numerical simulation.
\end{abstract}

\section{Introduction}

Since the second half of the 1990s there is a renewed interest in the modeling of concrete at high and very high temperature [1-2]. Studies on bond stress between concrete and deformed bars show that bond stress is made up of three components namely: (1) chemical adhesion; (2) friction; and (3) mechanical interaction between concrete and steel [3-4].

Due to the complexity of the external loads of concrete structures, the damage of the three mentioned components which has not been determined explicitly is different. For example, the loss of chemical adhesion after evaluated temperatures can not been well reflected by traditional test method. The understanding and the modeling of the interfaces is actually one of the challenges of Civil Engineering. It concerns as well the classical techniques in masonry (including antique monuments) as the new techniques used either in assembling or repairing structures or developing new reinforced concrete adapted to strong solicitations [5]. Experimental study of the interaction between concrete and a bar subjected to a pull out force shows that bond evolve progressively from perfect adhesion to dry friction type [6]. Chemical adhesion, one of composition of bond strength at the interface of concrete and steel, is affected by concrete mix proportion, age of the concrete substrate, curing conditions and other factors. Campione pointed out that the chemical adhesion between concrete and steel bar should less than 1.2MPa [7]; Xu completed a series of experiments and found that the chemical adhesion should be $0.4 \sim 0.6 \mathrm{MPa}$ [8], Gao recommended the chemical adhesion should be $1 \sim 3 \mathrm{MPa}$ [9]. Inspection of the literature found by different scholars, there are some discrete in the research results on the same subject. Moreover, previous experience has been only studied the shear strength at room temperature, but little research has been done after evaluated temperatures.

Furthermore, finite element software ANSYS, ABAQUS have access to contact analysis [10-11]. However, the interface parameters are often selected based on experience. In view of the particularity and complexity of the bond-slip relationship, this paper presents an experimental study on the chemical adhesion between HPC and rolled steel plate after evaluated temperatures. The result of this paper can provide necessary parameters for strengthen concrete structures after fire or finite element simulations. 


\section{Shear-off specimen design}

HPC mix proportion are listed in table1.

Table 1 Mix proportion of C100 concrete

\begin{tabular}{|c|c|c|c|c|c|c|}
\hline \multicolumn{6}{|c|}{ A variety of materials consumption per cubic meter of concrete/(kg.m-3) } & \multirow[b]{2}{*}{ m Slump/m } \\
\hline $\begin{array}{r}\text { Slag } \\
\text { cement }\end{array}$ & Slag & Silicon & $\begin{array}{c}\text { Wa Sa } \\
\text { ter nd }\end{array}$ & Grave $(5 \sim 15 \mathrm{~mm})$ & $\begin{array}{c}\text { Super } \\
\text { plasticizer }\end{array}$ & \\
\hline 420 & 120 & 60 & 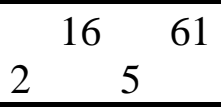 & 1140 & 9.526 & 200 \\
\hline
\end{tabular}

Mixing process is as follows: First put into cement, slag, silica fume, sand and gravel, stirring about 2min, mix evenly by adding half of the water, then add the other half of the water and the water-reducing agent, stirring for 3 4min before the discharge. Through relevant tests, the concrete produced by the ratio and the mixing process above has good workability and durability.

Specimen with dimension of $100 \mathrm{~mm} \times 100 \mathrm{~mm} \times 150 \mathrm{~mm}$ was casted in a special mold. Two $5 \mathrm{~mm}$ thick steel plate were pasted on both left and right surface of the specimen. After the form removal, the specimens were cured in water $\left(20 \pm 3^{\circ} \mathrm{C}\right)$ in the conservation room. 28 days later, they were placed indoors for natural drying. Another month later, the specimens were tested. Specimens were divided into 4 groups (G1 G4), each group including 6 specimens corresponding to 6 temperature conditions. Fig.1 demonstrates the shear specimen.

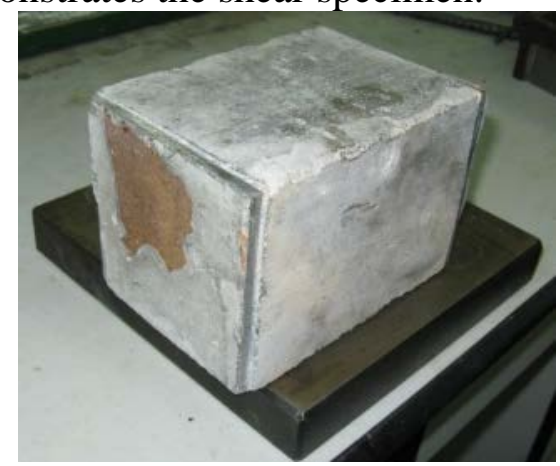

Fig.1 Cementation shear specimen

\section{Shear strength after elevated temoperatures}

Shear strength test was carried out on TSY-2000 electric hydraulic pressure testing machine, see Fig.2. The schematic diagram is displaced in Fig.3.

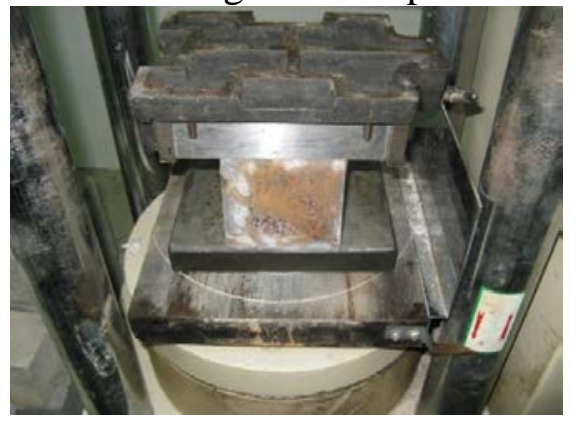

Fig.2 Test equipment

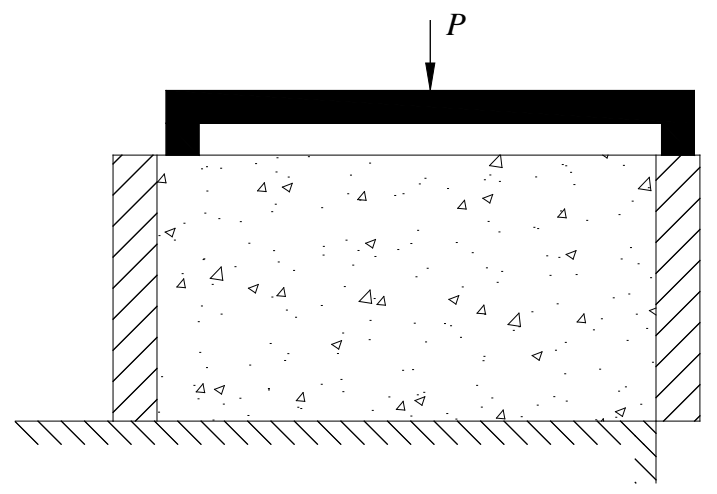

Fig.3 Schematic diagram

Vertical load P was recorded while the plate had been sheared off. The loading rate should less than $0.5 \mathrm{kN} / \mathrm{sec}$. The average bond shear strength of concrete can be obtained with the following formula:

$$
\tau_{a}=\frac{P}{2 A}
$$

The variations of shear strength with the evaluated temperatures are shown in Fig.4t. Shear strength can be seen with a significant linear relationship with the evaluated temperatures. 


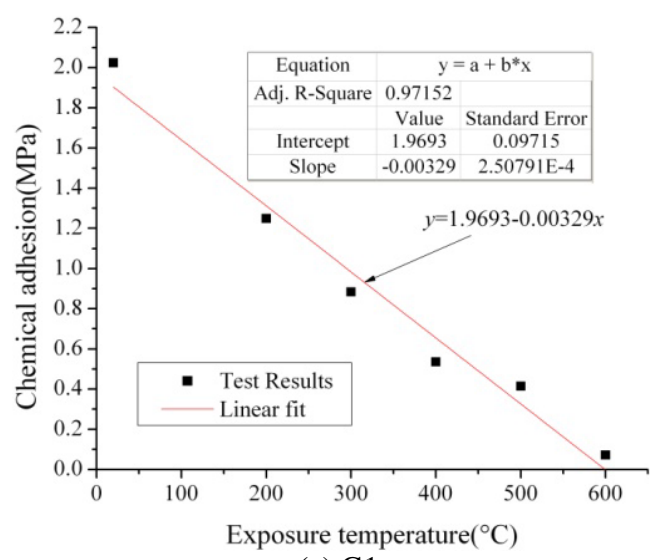

(a) G1

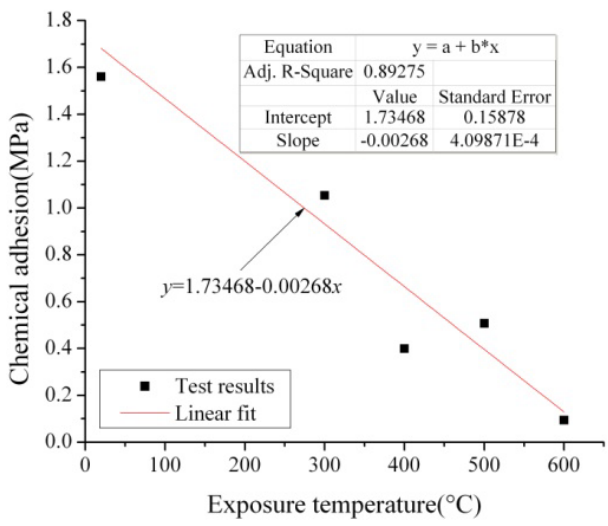

(c) G3

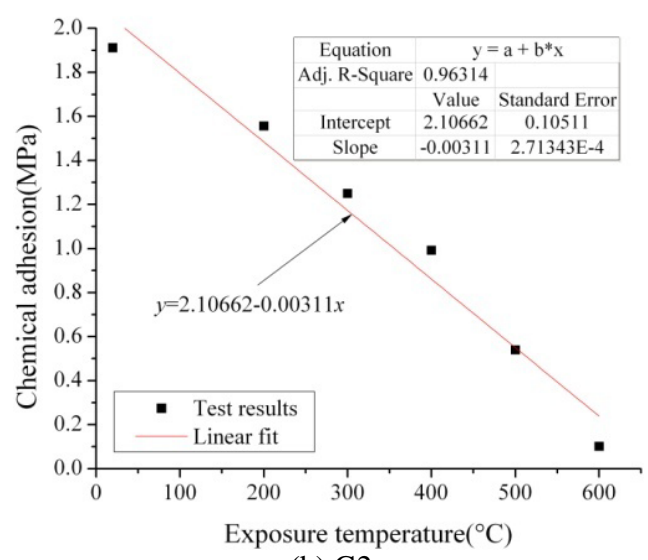

(b) G2

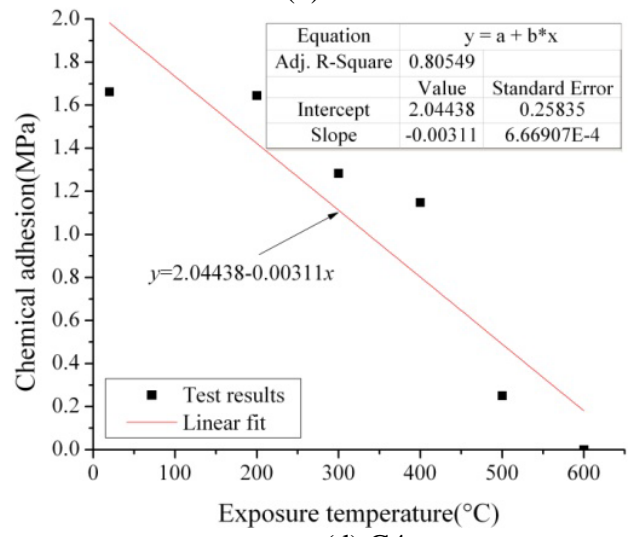

(d) G4

Fig.4 Shear strength variation with evaluated temperatures

Shear strength between HPC and rolled steel decreases with increasing temperatures. The trends can be expressed as a linear function:

$$
\tau_{a}=a+b \times T
$$

Where $\mathrm{T}$ is the experienced temperature, the range of $\mathrm{a}$ is 1.73468 2.10662, while the range of $\mathrm{b}$ is $-0.00311 \sim-0.00268$. However, test results show that the rolled steel plate would be off because of uneven expansion when the experienced temperature is higher than $400{ }^{\circ} \mathrm{C}$, which would result in an increase of the coefficient of variation. Therefore, in the conservative consideration, the author recommended that bond-slip problem should no longer include in the focus of adhesion when the exposed temperature is higher than $400{ }^{\circ} \mathrm{C}$.

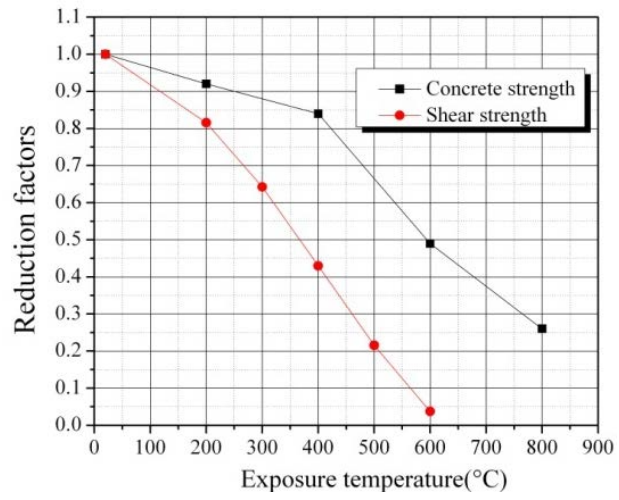

Fig.5 Reduction factors of concrete strength and shear strength after evaluated temperatures

Reduction factors of concrete strength and shear strength are graphically presented in Fig.5. It can be seen from the picture that reduction factors of concrete strength and shear strength were reduced as the exposure temperature was increased. The reduction factors of concrete strength versus temperature decrease slightly before $400{ }^{\circ} \mathrm{C}$, yet sharply at temperatures greater than $400{ }^{\circ} \mathrm{C}$. Besides, the reduction factors of shear strength should always lower than that of concrete strength after evaluated temperatures. 


\section{Conclusions}

In this paper, shear strength between HPC and rolled steel plate after evaluated temperatures was experimentally studied. Based on the test result and relative analysis, the following conclusions are obtained:

1. Compressive strength of HPC would decrease with increasing temperatures.

2. Shear strength between HPC and rolled steel decreases with increasing temperatures. Bond-slip problem should no longer include in the focus of adhesion when the exposed temperature is higher than $400{ }^{\circ} \mathrm{C}$.

3. The decrease trends of shear strength between HPC and rolled steel can be expressed as a linear function.

4. The reduction factors of shear strength should always lower than that of concrete strength after evaluated temperatures.

\section{Acknowledgements}

The financial support from the National Natural Science Foundation of China (51474218) is greatly acknowledged.

\section{References}

[1] Xiao J., Falkner H. (2006). On residual strength of high-performance concrete with and without polypropylene fibers at elevated temperatures. Fire Safety Journal, 41:5, 115-121.

[2] Xiao J., Li J., Jiang F. (2004). Research on the seismic behavior of HPC shear walls after fire. Materials and Structures, 37:1, 506-512.

[3] FIB Bulletin No. 10. (2000). Bond of reinforcement in concrete. State-of-art Report, Fédération Internationale du Béton, Federal Institute of Technology. Lausanne Switzerland: Département Génie Civil.

[4] Wang X., Liu X. (2006). Bond strength modeling for corroded reinforcements. Construction and Building Materials, 20:6, 177-186.

[5] Raous M., Karray M. A. (2009). Model coupling friction and adhesion for steel-concrete interfaces. International Journal of Computer Applications in Technology, 34:1, 42-51.

[6] Gambarova P. G. (1988). Test results and constitutive relationships for steel to concrete bond after concrete splitting. Seminars of structure engineering 1988, 27 April 1988.

[7] Campione G., Cucchiara C., Mendola L. L. et.al. (2005). Steel-concrete bond in lightweight fiber reinforced concrete under monotonic and cyclic actions. Engineering Structure, 27:3, 881-890.

[8] Xu Y., Shen W., Wang H. ( 1994). An experimental study of bond-anchorage properties of bars in concrete. Journal of Building Structures, 41:5, 26-36.

[9] Gao X. ( 2004). Test and simulation of bond performance between high-performance concrete and steel bars. Shanghai: Tongji University.

[10] ANSYS Inc. (1998). ANSYS user’s manual (Versions 6.0 to 8.1). Canonsburg, 1998-2003.

[11] Li H., Liu Z. Q., et al. (2007). Study on reinforced concrete beams strengthened using shape memory alloy wires in combination with carbon-fiber-reinforced polymer plates. Smart Materials \& Structures, 16:6, 2550-2559. 